\title{
Self-Efficacy and Academic Motivation of Students in a Catholic High School with Parents Working Abroad
}

\author{
Patrick Daren S. Campos ${ }^{1}$ and Dennis V. Madrigal ${ }^{2}$ \\ ${ }^{1}$ St. Therese's High School Inc., Anini-y, Antique, Philippines \\ ${ }^{2}$ University of Negros Occidental-Recoletos, Bacolod City, Philippines
}

\begin{tabular}{l} 
Article history \\
Submitted: 26 October 2020 \\
Revised: 2 November 2020 \\
Accepted: 12 November 2020 \\
\hline Keywords \\
Guidance and Counseling \\
Self-Efficacy \\
Academic Motivation \\
High School Students \\
Parents Working Abroad \\
Catholic School \\
Descriptive-Correlational \\
Antique
\end{tabular}

Accepted: 12 November 2020

\section{Keywords}

Self-Efficacy

Academic Motivation

Catholic School

Antique

\section{Article history}

Introduction. Psychologists argue that individuals' choice, persistence, and drive expended in performance can be predicted and explained basically by their self-efficacy and motivation. Research on selfefficacy theory has examined the contribution of students' emerging perceptions of their academic abilities, and confidence that they can finish specific academic tasks, predictions about educational outcomes, and interpretation of success and failure experiences. Hence, the study intends to assess the level of one's capability to achieve and accomplish specific tasks and factors that might influence their motivation towards the academic performance among students in a Catholic high school in Antique with parents working abroad. Likewise, it explores whether self-efficacy relates to the academic motivation of students.

Methods. The descriptive, comparative, and correlational design were utilized to assess, compare, and correlate self-efficacy and academic motivation of 110 high school students in a Catholic School in the province of Antique with parents working abroad for the school year 2019-2020. They were classified according to sex, academic performance, academic level, family monthly income, and membership in school organizations/clubs. Respondents were identified using systematic sampling. They answered two standardized questionnaires, the self-efficacy scale, and the academic motivation scale. The Mean, Standard Deviation, frequency count, percentage distribution, Mann Whitney U Test, and Spearman rank correlation were used for data analysis.

Results. The findings revealed that students demonstrated a high level of self-efficacy for learning with test preparation, note-taking, and writing as the highest and lowest areas. When grouped according to demographics, high school students also showed a high level of self-efficacy for learning regardless of sex, academic performance, academic level, family monthly income, and membership in school organizations/clubs. Moreover, the results showed that high school students demonstrated very high academic motivation with extrinsic motivation and amotivation as the highest and lowest types, respectively. A significant difference was found in the level of self-efficacy of high school students when grouped according to sex and academic performance. There was no significant difference in the level of academic motivation of high school students when categorized according to sex, academic level, and family monthly income. Moreover, there was a significant relationship between self-efficacy and academic motivation of high school students.

Conclusion. High school students in a Catholic school in Antique with parents working abroad generally are efficacious and academic-motivated. Their high levels of self-efficacy and academic motivation indicate their competencies and capabilities to accomplish and perform specific tasks assigned to them. Being efficacious and motivated are essential ingredients to prepare them in accomplishing academic tasks with determination. High levels of self-efficacy and self-determination are good indicators to succeed in school. However, external factors such as social support, rewards, and incentives for accomplishing a specific task or outcome may strengthen the extrinsic behavior in attaining the goal. Furthermore, the relationship between self-efficacy and academic motivation significantly influences students' competence and confidence to perform school tasks. Both parents and teachers play essential roles in this aspect to develop and enhance the desires and capabilities in attaining holistic transformation. 
Practical Value of the Paper. The study significantly adds to the literature about self-efficacy and its relation to the academic motivation of high school students in a Catholic school in Antique. In addition, this benefits school administrators and guidance personnel to design and implement programs that will enhance students' self-efficacy and academic motivation.

\section{References}

Dogan, U. (2015). Student engagement, academic self-efficacy, and academic motivation as predictors of academic performance. The Anthropologist, 20(3), 553-561.

Gbollie, C., \& Keamu, H. P. (2017). Student academic performance: The role of motivation, strategies, and perceived factors hindering Liberian junior and senior high school students learning. Education Research International, 2017.

Ibrahim, M., Baharun, H., Harun, H., \& Othman, N. (2017). Antecedents of Intrinsic Motivation, Metacognition and Their Effects on Students' Academic Performance in Fundamental Knowledge for Matriculation Courses. Malaysian Journal of Learning and Instruction, 14(2), 211-246.

Kasilag, R. (2015). Relationship between parent's overseas work on the left-behind children's quality of life and career choice intention. Accessed at uniqueca. com/archives/wp-content/uploads/2015/01/Renan-kasilag. pdf.

Korantwi-Barimah, J. S., Ofori, A., Nsiah-Gyabaah, E., \& Sekyere, A. M. (2017). Relationship between motivation, academic self-concept, and academic achievement amongst students at a Ghanaian Technical University. International Journal of Human Resource Studies, 7(1), 61-73.

Maddux, J. E. (2016). Self-efficacy interpersonal and intrapersonal expectancies. Abingdon: Routledge.

Ricard, N. C., \& Pelletier, L. G. (2016). Dropping out of high school: The role of parent and teacher self-determination support, reciprocal friendships, and academic motivation. Contemporary Educational Psychology, 44, 32-40.

Schwarzer, R. (Ed.). (2014). Self-efficacy: Thought control of action. Taylor \& Francis.

van Rooij, E. C., Jansen, E. P., \& van de Grift, W. J. (2017). Factors that contribute to secondary school students' self-efficacy in being a successful university student. ReseaRch in Post-comPulsoRy education, 22(4), 535-555.

Villas, J. (2019). Self-Efficacy of Filipino Senior High School Students: Differences among Tracks/Strand and Type of School. Journal of Education and Practice, 10(8).

\section{Correspondence:}

Patrick Daren S. Campos [patrickdarencampos104@gmail.com]

https://orcid.org/0000-0002-1248-9726 